GA-A23753

\title{
COMPOSITION AND STRUCTURAL STUDIES OF STRONG GLOW DISCHARGE POLYMER COATINGS
}

\author{
D.G. CZECHOWICZ, E.R. CASTILLO, and A. NIKROO
}




\section{DISCLAIMER}

This report was prepared as an account of work sponsored by an agency of the United States Government. Neither the United States Government nor any agency thereof, nor any of their employees, makes any warranty, express or implied, or assumes any legal liability or responsibility for the accuracy, completeness, or usefulness of any information, apparatus, product, or process disclosed, or represents that its use would not infringe privately owned rights. Reference herein to any specific commercial product, process, or service by trade name, trademark, manufacturer, or otherwise, does not necessarily constitute or imply its endorsement, recommendation, or favoring by the United States Government or any agency thereof. The views and opinions of authors expressed herein do not necessarily state or reflect those of the United States Government or any agency thereof. 
GA-A23753

\title{
COMPOSITION AND STRUCTURAL STUDIES OF STRONG GLOW DISCHARGE POLYMER COATINGS
}

\author{
by \\ D.G. CZECHOWICZ, E.R. CASTILLO, and A. NIKROO
}

This is a preprint of a paper to be presented at the 14th Target

Fabrication Meeting, July 15-19, 2001 West Point, New York and to be published in Fusion Technology.

\author{
Work supported by \\ the U.S. Department of Energy \\ under Contract No. DE-AC03-01SF22260
}

GA PROJECT 30095

APRIL 2002 


\title{
COMPOSITION AND STRUCTURAL STUDIES OF STRONG GLOW DISCHARGE POLYMER COATINGS
}

\author{
D.G. Czechowicz, E. R. Castillo, and A. Nikroo \\ Inertial Fusion Technology \\ General Atomics, P.O. Box 85608, San Diego, California 92186-5608 \\ (858) 455-2897, email: donald.czechowicz@gat.com
}

\begin{abstract}
An investigation of the chemical composition and structure of strong glow discharge (GDP) polymer shells made for cryogenic experiments at OMEGA is described. The investigation was carried out using combustion and Fourier Transform Infrared Spectroscopy (FTIR) analysis. The strongest coatings were observed to have the lowest hydrogen content or hydrogen/carbon $\mathrm{H} / \mathrm{C}$ ratio, whereas the weakest coatings had the highest hydrogen content or $\mathrm{H} / \mathrm{C}$ ratio. Chemical composition results from combustion were used to complement FTIR analysis to determine the relative hydrogen content of as-fabricated coatings. Good agreement was observed between composition results obtained from combustion and FTIR analysis. FTIR analysis of coating structures showed the strongest coatings to have less terminal methyl groups and a more double bond or olefinic structure. Strong GDP coatings that were aged in air react more with oxygen and moisture than standard GDP coatings. In addition to a more olefinic structure, there may also be more free-radical sites present in strong GDP coatings, which leads to greater oxygen uptake.
\end{abstract}

\section{INTRODUCTION}

Thin wall, high-strength polymer shells are currently required in the production of direct drive targets for OMEGA cryogenic experiments. The shells of interest are approximately $900 \mu \mathrm{m}$ in diameter and typically $1-2 \mu \mathrm{m}$ in wall thickness. High-strength and permeability are required to allow filling of the target with DT (deuteriumtritium) to a pressure of about $1000 \mathrm{~atm}$ as quickly as possible. Shells with greater buckling pressures and permeabilities can be filled faster. In addition, the shells must be robust for routine handling. In this paper, we present results of our study of the relationship between composition and structure of the polymer coating and the resulting strength.

\section{EXPERIMENTAL}

Thin wall GDP shells were made by the depolymerizable mandrel technique using poly-alphamethylstyrene (PAMS) mandrels. ${ }^{1}$ The fabrication process and system hardware have been described previously. 2,3 In the deposition process trans-2-butene (T2B) is mixed with hydrogen, the T2B is broken down in the plasma region, and the hydrocarbon fragments deposit on substrates forming ultra-smooth coatings. Standard GDP coatings used for typical ICF capsules are produced using a system pressure of $75 \mathrm{mT}$ Torr. To obtain stronger coatings, deposition must be carried out at a lower system pressure, typically $20-25 \mathrm{mTorr}^{2}$ In addition, lower ratios of trans-2-butene to hydrogen flow are needed for deposition of stronger coatings at these lower pressures. ${ }^{4}$ Here we designate coatings deposited at higher pressure as high pressure-glow discharge polymer (HP-GDP), while coatings fabricated using lower system pressures are termed low pressure-glow discharge polymer (LP-GDP). For LP-GDP coatings the ratio of trans-2-butene to hydrogen flow was varied from 0.04 to 0.15 . The strength of GDP shells was determined by buckle testing. The technique and apparatus used for making buckle strength measurements on thin walled GDP shells has been described previously. ${ }^{2}$

FTIR analysis of the GDP coatings was performed using a Nicolet Instruments NEXUS 470 FTIR Spectrometer. We deposited thin 1.5 to $2.5 \mu \mathrm{m}$ GDP coatings for FTIR analysis directly onto $\mathrm{NaCl}$ optical crystal discs that were $13 \mathrm{~mm} \times 1 \mathrm{~mm}$, the $\mathrm{NaCl}$ discs were obtained from International Crystal Labs, Garfield, New Jersey. The discs were cleaned by the vendor, hermetically sealed, and used as-is. Sample thickness was measured by interferometry, which is usually accurate to $10 \%$. For direct comparison, the same coating conditions were used for both the production of shells and films. 
Coatings were fabricated in duplicate for quantitative FTIR analysis. The FTIR spectrometer was equipped with a condenser to reduce the beam diameter to $\sim 1.5 \mathrm{~mm}$. A sample-positioning jig ensured that the same central $1.5 \mathrm{~mm}$ diameter portion of each coating deposited on the $\mathrm{NaCl}$ discs was probed by the FTIR spectrometer. All spectra shown in this report are averages of 32 scans with a resolution of $4 \mathrm{~cm}^{-1}$. Since the system was not purged with $\mathrm{N}_{2}$, prior to obtaining a spectrum for each coating a background measurement was obtained and recorded using an empty sample holder to compensate for absorptions due to background water vapor and $\mathrm{CO}_{2}$.

GDP coatings fabricated using five different processing conditions were deposited on glass slides and analyzed for chemical composition using combustion analysis. 5 This was done to provide an independent measure of the relationship between deposition conditions and chemical composition.

Aging studies of the GDP coatings were also performed using FTIR analysis. In these studies, initial measurements were made on fresh coatings within a few minutes after removing samples from the coating system. The coatings were then aged by exposure to laboratory air, during which FTIR spectra were obtained after varying time intervals to as long as 60 days.

\section{RESULTS AND DISCUSSION}

\section{A. Coating Strength Analysis}

Systematic data was obtained for GDP strength as a function of coating process conditions. Results of GDP buckle strength measurements, were normalized for aspect ratio differences, ${ }^{2}$ and are presented in Fig. 1 . The data presented in Fig. 1 are for GDP shells fabricated using the exact same process and same batch of initial starting shell

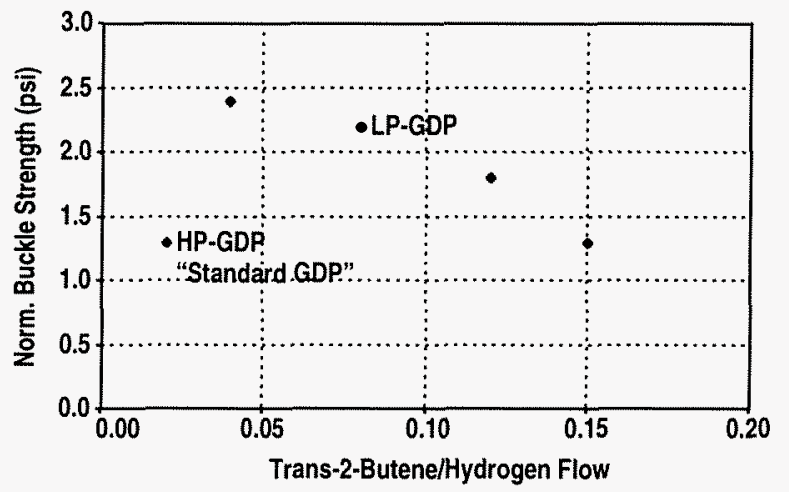

Fig. 1. Plot of average normalized buckle strength for various types of GDP shell batches versus $\mathrm{T} 2 \mathrm{~B} / \mathrm{H} 2$ flow ratio. The strength data were normalized and represent values for $900-\mu \mathrm{m}$ diameter, $1-\mu \mathrm{m}$ wall thickness shells. mandrels that had an average diameter of $920 \pm 5.0 \mu \mathrm{m}$. The strongest GDP shells are LP-GDP shells made at relatively low T2B/H2 flow ratio. The standard HP-GDP shells and LP-GDP shells made at progressively higher $\mathrm{T} 2 \mathrm{~B} / \mathrm{H} 2$ flow ratios are considerably weaker.

Fourier Transform Infrared Spectroscopy data was used to gain insight into relative hydrogen content and structural features present in the various GDP coatings. Representative FTIR spectra for as-fabricated GDP coatings produced for various deposition conditions are presented in Fig. 2.

Preliminary inspection of the FTIR spectra of Fig. 2 reveals a number of qualitative differences between the absorption spectra of strong and weak coatings. In the $\mathrm{CH}$ stretching region $\left(-2800-3100 \mathrm{~cm}^{-1}\right)$ the spectra of stronger coatings have a broad absorption at approximately $2900 \mathrm{~cm}^{-1}$ that includes a shoulder at $3020 \mathrm{~cm}^{-1}$. Spectra of weaker coatings have a narrower absorption at $2900 \mathrm{~cm}^{-1}$ and do not have a noticeable shoulder present at $3020 \mathrm{~cm}^{-1}$. In the $\mathrm{C}=\mathrm{C}$ stretching region, the stronger coatings have a sharper, more intense absorption at $1600 \mathrm{~cm}^{-1}$ compared to the weaker coatings. The sharp peak at $1380 \mathrm{~cm}^{-1}$ seen in the weaker coatings is practically absent in the strongest coating.

The FTIR spectra were then quantitatively analyzed to determine the relative hydrogen content for the coatings. The absorption peak centered at $2900 \mathrm{~cm}^{-1}$, which corresponds to $\mathrm{CH}$ stretching vibration, was integrated for each spectrum. The integrated area under the peak was then normalized for thickness to produce a value corresponding to a $1-\mu \mathrm{m}$ thick film. Other workers have also used this method to determine relative hydrogen content in hydrocarbon coatings during studies of diamond-like carbon films. ${ }^{6}$ Normalized $\mathrm{CH}$-stretching

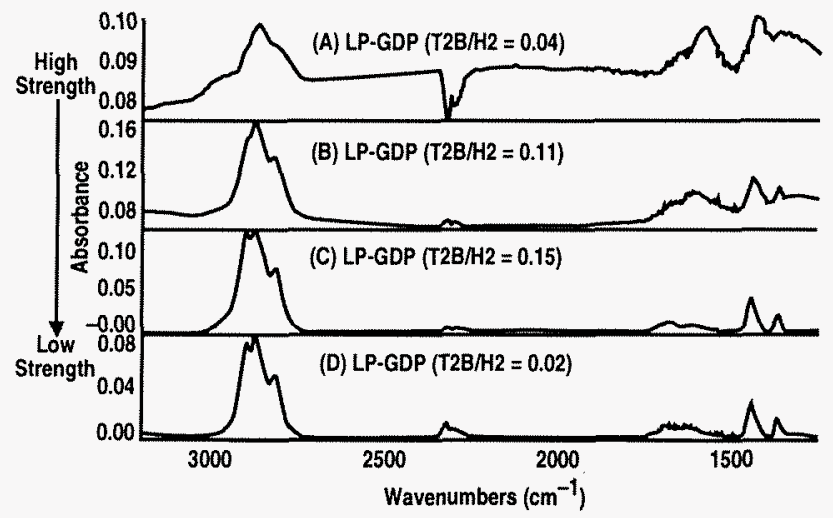

Fig. 2. FTIR absorption spectra from $3200-1200 \mathrm{~cm}^{-1}$ for various LP-GDP and HP-GDP coatings. Process conditions used to produce the various spectra are indicated above the individual spectra. 
peak-area data are plotted against the ratio of trans-2butene/hydrogen flow for both LP-GDP and HP-GDP coatings in Fig. 3. Process conditions that produce the weakest and strongest LP-GDP shells are also indicated in Fig. 3. From the figure, it is clear that the spectra of the strongest coatings, (LP-GDP coatings at the lowest $\mathrm{T} 2 \mathrm{~B} / \mathrm{H} 2$ flow) have the lowest $\mathrm{CH}$ absorption, which corresponds to the lowest hydrogen content. The weaker coatings have correspondingly larger $\mathrm{CH}$ absorption peaks indicating higher relative hydrogen content.

A plot of combustion analysis data in terms of $\mathrm{H} / \mathrm{C}$ ratio versus $\mathrm{T} 2 \mathrm{~B} / \mathrm{H} 2$ ratio is presented in Fig. 4. A trend similar to that found in the FTIR data is observed here as well. The combustion data validates integration of the FTIR CH absorption data in the $2900 \mathrm{~cm}^{-1}$ region as a quantitative way to determine relative hydrogen content in coatings. As the T2B/H2 ratio is increased, the LP-GDP coatings become more hydrogen rich or saturated. The strongest coatings (LP-GDP at the lowest $\mathrm{T} 2 \mathrm{~B} / \mathrm{H} 2$ ratio)

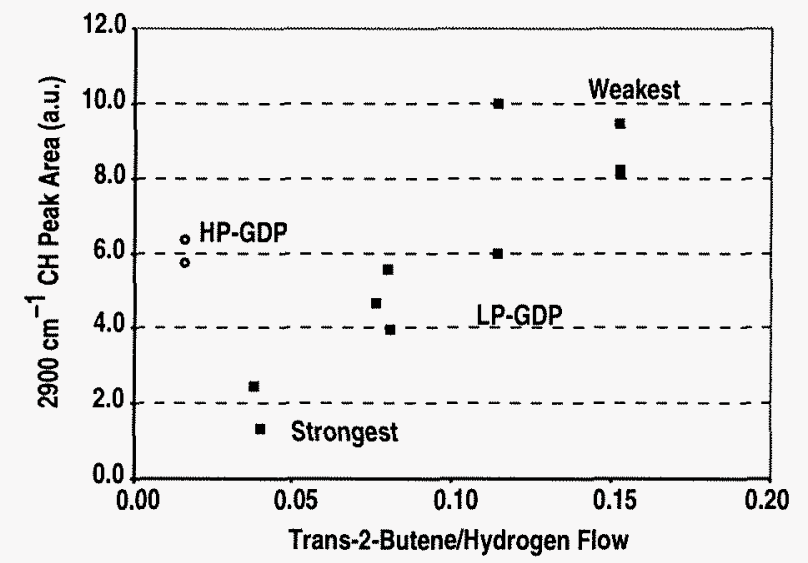

Fig. 3. FTIR integrated peak area for the absorption found at $2900 \mathrm{~cm}^{-1}$ for various GDP coatings produced using LP-GDP and HP-GDP processing conditions. The peak areas correspond to the absorption for a $1-\mu \mathrm{m}$-thick coating.

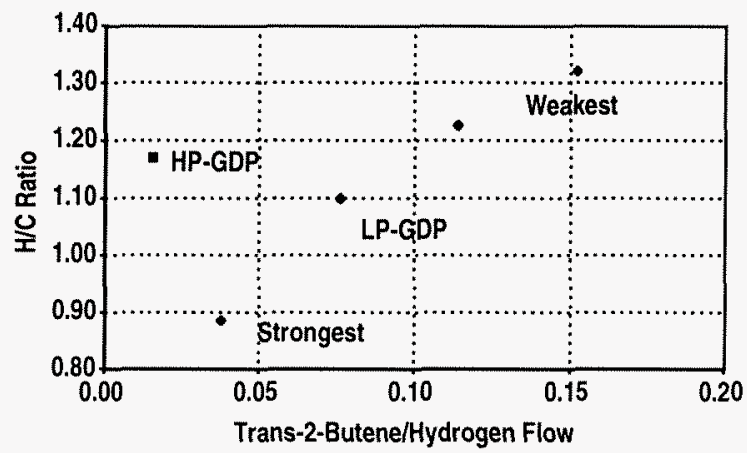

Fig. 4. Hydrogen/carbon ratio versus trans-2-butene flow for HP-GDP and LP-GDP coatings. The weakest LP-GDP coatings have a high $\mathrm{H} / \mathrm{C}$ ratio, whereas the strongest LP-GDP coatings have a low $\mathrm{H} / \mathrm{C}$ ratio. have the lowest $\mathrm{H} / \mathrm{C}$ value of 0.89 . At the highest $\mathrm{T} 2 \mathrm{~B} / \mathrm{H} 2$ ratio for LP-GDP conditions, a coating having an H/C value of 1.32 is produced. These coatings were observed to be the weakest. Standard HP-GDP is observed to have an intermediate $\mathrm{H} / \mathrm{C}$ ratio of 1.17 . Therefore the $\mathrm{H} / \mathrm{C}$ ratio for GDP coatings appears to correlate well with strength.

The $3200-2700 \mathrm{~cm}^{-1}$ region of the FTIR spectra for various GDP coatings can be further evaluated by deconvoluting the observed aggregate absorption peak. Other workers in studies of hard diamond-like films have discussed this procedure. ${ }^{7}$ When this procedure is carried out, the individual structural groups in the coating that make up the aggregate absorption can be determined. For example, a deconvolution of the $\mathrm{CH}$ absorption peak observed for a strong LP-GDP coating is presented in Fig. 5. The various peaks are labeled in the figure following the treatment described in Ref. 7. The FTIR absorption present at $2925 \mathrm{~cm}^{-1}$ arises both from sp $\mathrm{sH}^{3} \mathrm{CH}$ and $\mathrm{sp}^{3} \mathrm{CH}_{2}$ asymmetric (asym) vibrations. These two absorptions are overlapping at about $2925 \mathrm{~cm}^{-1}$ and therefore are too close to be resolved. This peak can indicate the amount of cross-linking present in the hydrocarbon-coating network. Likewise, two overlapping absorptions produce the peak at $2860 \mathrm{~cm}^{-1}$, from sp $\mathrm{CH}_{3}$ symmetric (sym) and $\mathrm{sp}^{3} \mathrm{CH}_{2}$ (sym) absorptions. The absorption at $2960 \mathrm{~cm}^{-1}$ is a useful absorption peak that can provide insight into structure, since it arises solely from terminal methyl groups. Similarly the absorption peak at $3020 \mathrm{~cm}^{-1}$ arises solely from $\mathrm{CH}$ and $\mathrm{CH}_{2}$ vibrations from carbon-carbon double bonds or olefinic structural groups. Using this information, the $\mathrm{CH}$ stretching absorption observed in the various FTIR spectra were deconvoluted to yield the relative amounts of $\mathrm{sp}^{3}$ $\mathrm{CH}_{3}$ (terminal methyl) and $\mathrm{sp}^{2} \mathrm{CH}$ and $\mathrm{CH}_{2}$ (carbon double bond) character present in each type of coating. The deconvolution results obtained are presented in Fig. 6, along with average buckle strength results for GDP shells fabricated using process conditions indicated.

The results presented in Fig. 6 provide further insight into the structural composition of the strong and weak coatings. The strongest coatings have both the greatest amount of olefinic carbon double bond character $\left(\mathrm{sp}^{2} \mathrm{CH}\right.$ and $\mathrm{CH}_{2}$ ) and the least amount of terminal methyl groups $\left(\mathrm{sp}^{3} \mathrm{CH}_{3}\right)$. Further evidence for this can also be found in other parts of the spectrum. The larger absorption at $1600 \mathrm{~cm}^{-1}$ seen in Fig. 2 for strong coatings indicates a greater $\mathrm{C}=\mathrm{C}$ content. The absence of an appreciable absorption at $1380 \mathrm{~cm}^{-1}$, the $\mathrm{CH}_{3}$ bending absorption, indicates reduced $\mathrm{sp}^{3} \mathrm{CH}_{3}$ in the strong coatings. Carboncarbon double bonds may provide added strength to GDP coatings. Also, coatings that have a high percentage of terminal methyl groups would have less carbon present in 


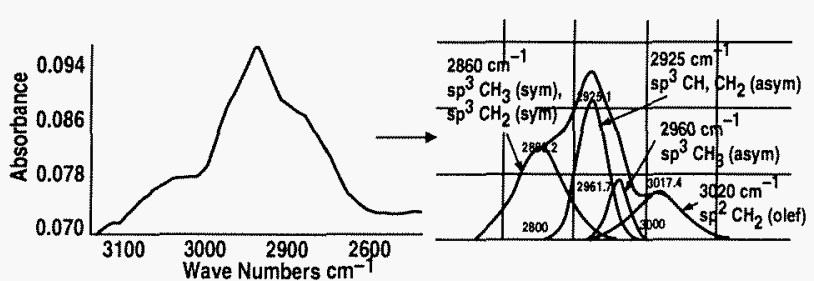

Fig. 5. Deconvolution of the FTIR absorption peak for $\mathrm{CH}$ stretching vibrations observed for a strong LP-GDP ( $\mathrm{T} 2 \mathrm{~B} / \mathrm{H} 2=0.04$ ) coating. Four structural features present in the coating produce the absorption observed in the $3200-2700 \mathrm{~cm}^{-1}$ spectral region

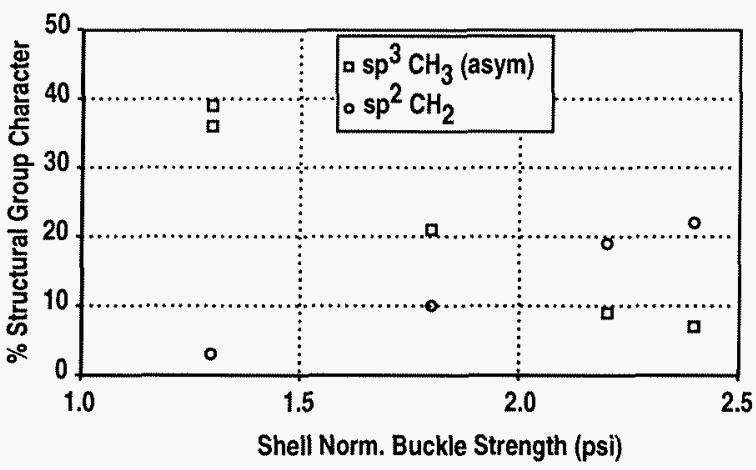

Fig. 6. GDP shell buckle strength data as a function of $\mathrm{sp}^{2} \mathrm{CH}_{2}$ and $\mathrm{sp}^{3} \mathrm{CH}_{3}$ (asym) structured group character. Shell buckle strength increases as the $\mathrm{sp}^{2}$ (carbon double bond) character increases and the $\mathrm{sp}^{3}$ (terminal methyl group) decreases. The data were obtained using deconvolution of $\mathrm{CH}$ stretching absorptions as discussed in the text and as shown in Fig. 5.

the form of a carbon-carbon cross-linked network. Terminal methyl groups are dangling end groups; when present in large amounts they indicate reduced cross-linking and are a likely cause for diminished coating strength.

It is clear from the data presented that deposition at lower pressures and higher hydrogen-to-T2B ratios leads to coatings with higher carbon content and greater amounts of cross-linking. This is consistent with the higher buckle strength results observed on shells made using these conditions. We can speculate as to why such conditions lead to the structures and strengths observed. The usual explanation based on higher ion bombardment of substrates and the role of hydrogen as an etching agent proposed in studies on diamond-like coatings appears to be valid in this case as well. ${ }^{8,9}$ At the lower pressures, due to a longer mean free path, the ions can attain higher energies as they approach and impact the substrate. The larger relative atomic hydrogen concentration in the plasma for low $\mathrm{T} 2 \mathrm{~B} / \mathrm{H} 2$ flows can lead to removal of dangling $\mathrm{CH}_{3}$ groups in the form of methane, and therefore a reduction in the $\mathrm{CH}_{3}$ content of coatings and a higher degree of cross-linking.

\section{B. Aging Results}

Virtually all GDP coatings contain a certain number of free radicals trapped in the coating during deposition. The presence of these trapped free radicals is a natural consequence of the plasma deposition process. In fact, free radical polymerization is thought to be the dominant mechanism responsible for GDP film formation in the first place. ${ }^{10}$ When freshly deposited GDP coatings are exposed to air, trapped free radicals can react with oxygen to produce $\mathrm{OH}$ and $\mathrm{CO}$ structures in the coatings. Therefore, the $\mathrm{OH}$ and $\mathrm{CO}$ content of air aged GDP coatings can provide information about the initial free radical content of films. Following the aging process as a function time can supply reaction rate information. ${ }^{11}$ This procedure was performed for both the strong and standard GDP coatings over a six-month period. An example of FTIR spectral data from an aging study for a typical, strong, low-T2B/H2 flow, LP-GDP coating is presented in Fig. 7. As expected, there is a significant change in the chemical structure of the LP-GDP coating upon exposure to air over time. The broad feature centered at $3400 \mathrm{~cm}^{-1}$, which is assigned to the hydroxyl $(\mathrm{OH})$ vibrational stretch, grows over time as expected. At the same time, the absorption at approximately 2800 to $3000 \mathrm{~cm}^{-1}$, which corresponds to $\mathrm{CH}$ vibrational stretching, decreases in intensity. There is also a decrease in the $3020 \mathrm{~cm}^{-1} \mathrm{sp}^{2}$ olefinic shoulder. Lastly, an absorption peak at $1700 \mathrm{~cm}^{-1}$ (not shown in Fig. 7) corresponding to carbonyl (CO) stretching also increases over time.

We can plot the integrated FTIR-peak areas for the three absorptions that are changing most significantly with time $(\mathrm{CH}, \mathrm{OH}$, and $\mathrm{CO}$ stretching vibrations) to obtain time-dependent changes in the corresponding structural group. We present the time dependent results for the strong LP-GDP $(\mathrm{T} 2 \mathrm{~B} / \mathrm{H} 2=0.04)$ coating and a standard HP-GDP coating in Fig. 8. For both coatings, there is a dramatic increase in $\mathrm{OH}$ and $\mathrm{CO}$ and a noticeable decrease in $\mathrm{CH}$ during the first 30 days of aging. After 30 days, $\mathrm{OH}$ and $\mathrm{CO}$ continue to increase and $\mathrm{CH}$ decreases, but at much slower rates. When results for the coatings are compared with each other, the changes in $\mathrm{OH}, \mathrm{CO}$, and $\mathrm{CH}$ for the strong LP-GDP coating is approximately 2 times that of the HP-GDP coating based on the data presented in Fig. 8. The data was fit to single exponentials for each of the structural groups to determine the rate for the two types of coatings. The rates were found to be similar for the strong (LP-GDP) and weak (HP-GDP) coatings.

The oxygen uptake results provide another interesting comparison between the various types of coatings. The strong LP-GDP coating fabricated using T2B/H2 $=0.04$ had the greatest oxygen uptake. This may indicate a higher trapped free-radical content in these coatings, which can 


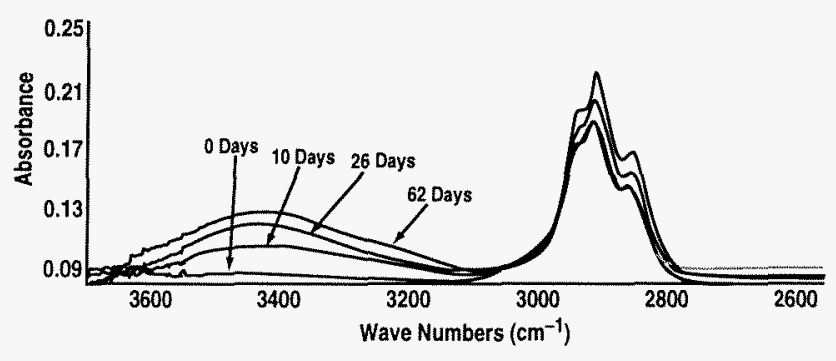

Fig. 7. FTIR absorption data for an LP-GDP coating produced with a $\mathrm{T} 2 \mathrm{~B} / \mathrm{H} 2$ flow ratio of 0.04 , as a function of exposure to air for various durations.

be expected given the greater amount of cross-linking present. The high oxygen uptake may also result from the greater number of double bonds present in this coating. The weaker HP-GDP coating had less oxygen uptake, which may indicate lower initial free-radical content consistent with the greater saturated hydrocarbon structure observed in these films.

\section{CONCLUSIONS}

Significant composition and structural differences exist between strong GDP coatings fabricated using lowpressure (20-25 mTorr) deposition conditions and standard HP-GDP coatings fabricated using high-pressure (75 mTorr) deposition conditions. There also exists composition and structural differences for LP-GDP coatings made using different ratios of trans-2butene/hydrogen flow. FTIR and combustion analysis data suggest that the strongest LP-GDP coatings have an H/C composition of less than 1.0 , which indicates a carbon rich structure. FTIR spectral data also indicate that the strongest LP-GDP coatings possess a significant amount of $\mathrm{sp}^{2}$ carbon or double-bond olefinic structure. Collectively, the strongest coatings have more double bonds, less terminal $\mathrm{CH}_{3}$ groups, and more carbon-carbon bonding or cross-linking. Weaker HP-GDP coatings have more hydrogen in their structure and an $\mathrm{H} / \mathrm{C}$ composition greater than 1.0. These weaker coatings have little double bond character and a more saturated hydrocarbon structure. The strong LP-GDP coatings exhibit greater oxygen uptake as a function of time. This may be the result of more of double bonds present in the coating, as well as a larger trapped free-radical content.

\section{ACKNOWLEDGMENT}

Work supported by the U.S. Department of Energy under Contract DE-AC03-01SF22260.
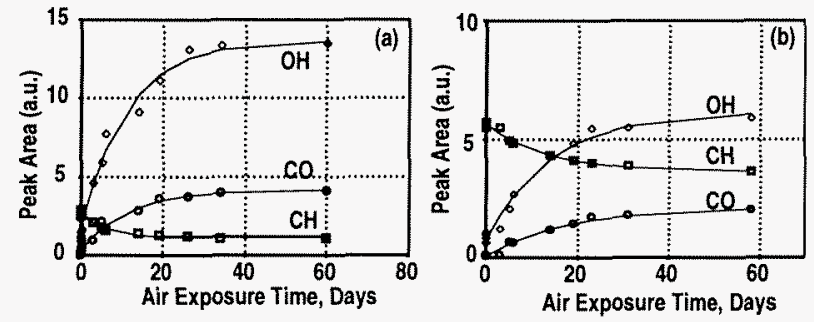

Fig. 8. Results of changes in FTIR absorption of $\mathrm{OH}, \mathrm{CH}$, and CO structural groups for a (a) strong LP-GDP and a (b) standard HP-GDP coating upon exposure to air over time.

\section{REFERENCES}

1. S.A. Letts, E.M. Fearon, S.R. Buckley, M.D. Saculla, L.M Allison, and R. Cook, "Fabrication of Polymer Shells Using a Depolymerizable Mandrel," Fusion Technol, 28, 1797 (1995).

2. A. Nikroo and J. Pontelandolfo, "Fabrication of Thin Walled Glow Discharge Polymer Shells," Fusion Technol. 38, 58 (2000).

3. S.W. Ferguson, R. Stever, and R.M. Brusasco, "ImpedencePower Effects on Plasma Polymer Surface Finish Using a Helical Resonator Discharge," J. Appl. Polym. Sci., 54, 107 (1994).

4. A. Nikroo, D.G. Czechowicz, E.R. Castillo, J.M. Pontelando, "Recent Progress in Fabrication of HighStrength Glow Discharge Polymer Shells by Optimization of Coating Parameters," these proceedings.

5. Desert Analytics, 245 South Plumer Avenue \#24, Tucson, Arizona 85719.

6. P.W. Pastel and W.J. Varhue, "The Effect of Radio Frequency Biasing in the Deposition of Diamond-Like Carbon Films in an Electron Cyclotron Resonance Discharge," J. Vac. Sci. Technol. 9, 1129 (1991).

7. B. Dischler, A. Bubenzer, and P. Koidl, "Bonding in Hydrogenated Hard Carbon Studied by Optical Spectroscopy," Solid State Commun., 48, No. 2, 105 (1983).

8. A. Bubenzer, et al., "RF-plasma deposited amorphous hydrogenated hard carbon thin films: Preparation, Properties, and Applications," J. Appl. Phys., 54, 4590 (1983).

9. M. Frenklach and K. Spear, "Growth Mechanism of VaporDeposited Diamond," J. Mater. Res. 3, 133 (1988).

10. H. Yasuda, "Plasma Polymerization," Chapter 6, Academic Press, Orlando, FL, (1985).

11. T.R. Gengenbach, Z.R. Vasic, R.C. Chatelier, and H.J. Griesser, "A Multi-Technique Study of the Spontaneous Oxidation of n-Hexane Plasma Polymers," J. Polym. Sci. A, Polymer Chemistry, 32, 1399 (1994). 